DOE/ER-0017

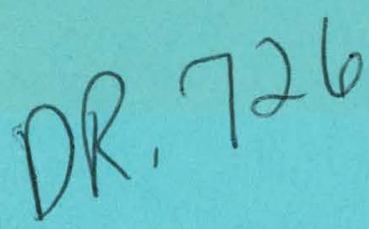

\title{
Review of the Future of the High Energy Physics Program at the Argonne National Laboratory
}

October 1978

U.S. Department of Energy

Directorate,Office of Energy Research

Division of High Energy Physics

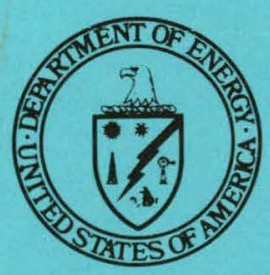




\section{DISCLAIMER}

This report was prepared as an account of work sponsored by an agency of the United States Government. Neither the United States Government nor any agency Thereof, nor any of their employees, makes any warranty, express or implied, or assumes any legal liability or responsibility for the accuracy, completeness, or usefulness of any information, apparatus, product, or process disclosed, or represents that its use would not infringe privately owned rights. Reference herein to any specific commercial product, process, or service by trade name, trademark, manufacturer, or otherwise does not necessarily constitute or imply its endorsement, recommendation, or favoring by the United States Government or any agency thereof. The views and opinions of authors expressed herein do not necessarily state or reflect those of the United States Government or any agency thereof. 


\section{DISCLAIMER}

Portions of this document may be illegible in electronic image products. Images are produced from the best available original document. 


\section{Review of the Future of the High Energy Physics Program at the Argonne National Laboratory}

October 1978

\section{U.S. Department of Energy}

Directorate,Office of Energy Research Division of High Energy Physics

Washington, D.C. 20545

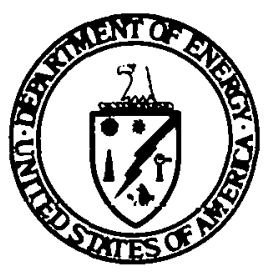

$$
\begin{aligned}
& \text { This report was prepared as an account of work } \\
& \text { spuriburied by" tho Unitod Stater Fonuemment Neither the } \\
& \text { United States nor the United States Department of } \\
& \text { Energy, nor any of their employees, nor any of their } \\
& \text { contractors, subcontrsctors, or their employees, makes } \\
& \text { any warranty, express or implied, or assumes any legal } \\
& \text { liability or responsibility for the accuracy, completeness } \\
& \text { or usefulness of any information, apparatus, product or } \\
& \text { process disclosed, or represents that its use would not }
\end{aligned}
$$


Avallable from:

National Technical Information Service (NTIS)

U.S. Department of Comnerce

5285 Port Royal Road

Springfield, Virginia 22161

Price: $\quad$ Printed Copy: $\$ 4.50$

Microfiche: $\$ 3.00$ 
Transmittal Letter -

S. Dre11, Chairman, HEPAP (SLAC) to J. Deutch, Director, Energy Research (DOE), September 25, 1978

Report of the HEPAP Subpanel on the Future of the High Energy Physics Program at Argonne

Report of the Evaluation Group on the Proposed Argonne

II $-\mathbf{i}$ National Laboratory Experimental Polarized Proton Storage Ring 


\section{THIS PAGE \\ WAS INTENTIONALLY \\ LEFT BLANK}




\section{Background}

At its meeting on February 9-11, 1978, the High Energy Physics Advisory Panel (HEPAP) established a subpanel to "review the future of the high energy physics program at the Argonne National Laboratory (ANL) following the shutdown of the ZGS." That subpanel, chaired by Francis Low, asked that a second group be convened to explore cost and scheduling questions relative to the proposed Polarized Proton Storage Ring (PPSR) project. The second group, the Evaluation Group on the Proposed Argonne National Laboratory Polarized Proton Storage Ring, was chaired by Dr. Richard Neal.

At $i$ ts meeting on August 8, 1978, HEPAP reviewed these two reports with the chairmen and came to a conclusion on recommendations for the ANL post-ZGS program in high energy physics. The final wording of HEPAP's recommendation and transmittal letter was reviewed during the September 24-25, 1978, meeting and is included here together with the two reports. 
THIS PAGE

\section{WAS INTENTIONALLY LEFT BLANK}


Stanford lineak Accelerator Centign

Dir: John Deutch, Director

Energy 'Research

Department of Energy

Old Executive office Bullding

Washtington, D. C. 20545

Dear John:

I an transmitting herewith the report of the sub-group established by HEPAP to review the future of the high energy physics program at the Argonne National Laboratory following the shutdown of the ZGS. HEPAP discussed this report and its recommendations as submitted by Francis Low, and also the report oubmitted by Richard Neal for the Evaluation Subcomittee, in considerable detall at its meeting on August 8, 1978 at the Stanford Linear Accelerator Center. The report of the Low Committee contains three specific recomendations. I will discuss these individually and give the HEPAP recomendation.

1. The first recomendation 18 to continue the strong in-house Argonne experimental and theoret 1cal high-energy research program. The experimental effort will henceforth operate in the user mode at accelerators at the other national factlities. HEPAP fully endorses this recommendation which is based on the displayed otrengths and achievements of the high energy research program at Argonne. We believe this research effort should continue to be supported in competition with theoretical and experimental user groups in the overall U.S. national program. Future budgets and level of effort should be measured agalnst standards of continued high productivity as set by the approved and ongoing experimental program at the national accelerators.

2. The second recommendation is that the Argonne Nat1onal Laboratory continue, on a trial basis, to make avallable its support fac1l1ties for untiversity users. It is not clear to HEPAP at this time what level of use will be made of these facilitles, which can be important asiets in the natlonal high energy program. Hence, in accord with the Low Comittee recommendations, HEPAP views this as an experimental and low-ievel commitment to be monitored on a year-by-year basis. If strong support exigts within the high energy program to utilize these valuable facllitles, which we see no need to try to duplicate at university user bases, then we axe pleased that Argonne 18 interested in maintalning them for a user base. On the other hand, we all recognitze the danger of 
creating a structure not based on a genuine need in the outside user community or not given a high priority by the ANL administration in competition with other Laboratory needs. Therefore, we accept this recommendation in the spirit in which it was made; namely, as a low-level trial commitment to see how the situation develops.

3. The third recommendation by the Low Comittee endorses the accelerator R\&D proposal including the transfer of the magnets and some additional components of the Penn-Princeton Accelerator to Argonne for constructing a polarized proton etorage ring (PPSR) which would be devoted to R\&D on the storage and acceleration of polarized protons in an alternating gradient accelerator. This recommendation recelved the most extensive critical discussion at the HEPAP meeting. We recognize and applaud the very strong merits and accomplishments of the excellent accelerator R\&D group at Argonne. We feel that it is important for this group to continue and to remain a vital component as we strive for future advances in accelerator technology beyond the immediate accelerator issues in our current program. However, given the realities of existing funding levels and restraints on the national program, HEPAP does not support the commitment of funds for the construction of the PPSR at this $t$ ime. Two factors were discussed intensively and extensively by HEPAP in arriving at this recommendation:

a) If the PPSR profect were supported, it would indeed be the focus of an important national effort to understand the problems and possibilities of storing and accelerating high energy polarized proton beams. However the users of this development would he the alternating gradient accelerators at BNL and at Fermilab aud some of the depolarizing effects are very accelerator specific.

b) Looking ahead in the national program, we also see other important, unfilled needs in accelerator R\&D leading toward high energy proton cooling and otorage, to superconducting RF for higher energy electron rings, to higher magnetic field etrengths and hence higher beam energies, and to a more rapid conversion of the AGS into a high quality ISABELLE injector.

In view of this situation HEPAP makes the following recommendation concerning accelerator R\&D: the excellent accelerator R\&D group at Argonne should continue to recelve support and encouragement to work closely in collaboration with Brookhaven and Fermilab so that the natlonal program not lose thelr singular talents. We belleve it is important that their work toward achieving polarized proton beams at high energies be coordinated with BNL and Fermilab who 
would be immediate customers of any R\&D achievements. We do not support the initiation of the PPSR profect at this time.

HEPAP is concerned that, under budgetary pressure and the pressure of users, accelerator R\&D at each of the national laboratories has tended to focus too specifically on the short range problems that are imediately at hand. However the future strength and vitality of the U.S. high energy program mandates the necessity of giving proper emphasis to long range accelerator R\&D and to looking to the generation after next in accelerator improvements. Consequently I am appointing a HEPAP subcomittee to review the balance, the depth, the quality, and the adequacy of the U.S. accelerator R\&D effort. We rely on this component of the national program to open new avenues for future accelerator technologies which are critically important for providing future advanced accelerator and experimental capabilities.

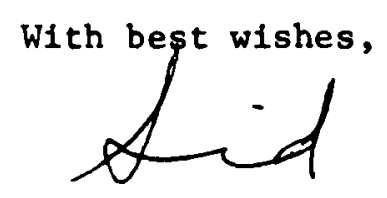

Sidney D. Drell

Chairman, HEPAP

SDD : br 


\title{
REPORT OF THE HEPAP SUBPANEL
}

\author{
ON THE
}

FUTURE OF THE HIGH ENERGY PHYSICS PROGRAM AT ARGONNE

Members

F. Low, MIT (Chairman)

E. Courant, BNL

R. Dlebuld, ANL

D. Meyer, Michigan

R. Neal, SLAC

T. O'Halloran, Illinois

J. Peoples, Fermilab

G. Trilling, LBL 


\section{THIS PAGE WAS INTENTIONALLY LEFT BLANK}


MASSACHUSETTS INSTITUTE OF TECHNOLOGY

DEPARTMENT OF PHYSICS

CAMBRIDGE. MASSACHUSETTS 02139

7 July 1978

Professor S. Drell

Chairman, HEPAP

SLAC

PO Box 4349

Stanford, CA 94305

Dear Sid:

I enclose the report of the HEPAP subpanel on the Future of the HEP Program at ANL.

The subpanel held a preliminary meeting in Germantown on May 4, coincident with the HEPAP meeting on that day, and then met again on May 20, 21 and 22 at ANL.

The subpanel members were E.D. Courant of Brookhaven National Laboratory, R.E. Diebold of ANL, D.I. Meyer of University of Michigan, R.B. Neal of SLAC, T. O'Halloran of University of Illinois, J.H. People of Fermilab, G.H. Trilling of LBL and myself. R. Woods of D.O.E. was with us throughout our deliberations. We also were generously helped by the ANL staff, especially G. Smith, M. Derrick and R. Martin.

Yours sincerely,<smiles>CCCCC[Te]C</smiles>

Francis E. Low

FEL/mat 
Report of the HEPAP Subpanel

on the

Future of the High Energy Physics Program at Argonne

I. The charge to the Subpanel was to give a formal opinion to the Department of Energy (DOE), through the High Energy Physics Advisory Panel (HEPAP); on the role of Argonne National Laboratory (ANL) in the national high energy physics (HEP) program after the shutdown of the Zero Gradient Synchrotron (ZGS). The experimental and theoretical high energy physics groups at ANL have made major contributions to the national program and we believe that in the post-ZGS period they will continue to be productive; the experimentalists as user groups at other accelerators and the theorists at home. HEP funding at ANL should be commensurate with this new role. The accelerator group has for several years been involved in a very successful program of polarized beam work. The resulting expertise should be directed toward research and development projects which will ultimately lead to polarized beam capabilities at other accelerators.

Because of the close proximity of ANL to Fermi National Accelerator Laboratory (Fermilab) much of the future ANL high energy physics program should logically be centered at Fermilab. We believe there are a number of areas where a closer cooperation between the Laboratories than has existed in the past could strengthen the national program as well as be of great benefit to both Laboratories. We would like to encourage such cooperation most strongly.

In the following paragraphs we detail our recommendations and address the specific question of the use of ANL as a support center for University user groups.

II. ANL has, since the construction of the ZGS, had an active and very productive research effort in high energy physics carried out by internal laboratory groups, both theoretical and experimental as well as by University-based user groups. The ANL internal effort has largeiy focussed on the ZGS, al though in recent years there has been involvement by ANL groups in various Fermilab collaborative experiments, and one of these groups now has a major role in. the construction of a large facility for the Positron-Electron Storage Ring Project (PEP) storage ring at Stanford Linear Accelerator Center (SLAC). It thus seems to be a natural transition, as the ZGS closes down, for these ANL research groups to continue a substantial user effort at other accelerator laboratories. Some of the benefits from a continuation of the HEP research effort of these groups are the following: 
(1) They provide a strength for the national HEP program which would probably be lost if no ANL user group effort were "continued.

(2) The outstanding shop facilities and engineering expertise available at ANL provide these groups, in collaboration with University groups, with the capability of building the very large and complex detectors and other facilities presently needed in many high energy physics experiments.

(3) The continued interaction of HEP with the diverse activities carried on at ANL in basic as well as applied research enhances the intellectual health of the laboratory.

The initial user group research effort in the post-ZGS period has the following components:

(1) The construction, in collaboration with several Unfversity groups, of a high resolution detector facility (PEP-12) for the study of positronelectron collisions.

(2) Participation in the design and construction of a colliding beam detector facility at Fermilab.

(3) The use of $\Lambda$ decay to develop a polarized proton secondary beam of modest but useful intensity at Fermilab, in collaboration with a number of other groups all interested in polarized proton work.

The first of these efforts has already received official approval as a PEP experiment and is well under way. With respect to the second project, Fermilab has committed itself to a goal of achieving colliding beams using the Energy Doubler and the present main ring. The specific decisions leading to the construction of a facility for colliding beam experiments will be forthcoming within the next year. The ANL group has actively participated in this work from the start. The third project, which is in a preliminary stage, has been presented to Fermilab as a proposal to construct a beam and to do an experiment with that beam. It is expected that the decision as to whether to carry out this project will be made within the year.

These projects represent natural extensions of the research interests and expertise developed by the ANL groups during the exploitation of 
the ZGS. The last two are evidently examples of projects which will benefit from a close cooperation between ANL and Fermilab.

In addition to the experimental efforts just described, a theoretical activity of roughly the same size as the present should continue. The ANL theory group has historically had a close and most useful interaction with the experimental program, and we are confident that this will also hold in the future.

The proposed level of support for HEP research, and for related experimental facilities research and development amounts to $\$ 4.5 \mathrm{M}(\$ 3.5 \mathrm{M}$ for research and $\$ 1 \mathrm{M}$ for R\&D). This level represents in our view a reasonable extension of the present support for these activities, but we cannot say at this time whether it is a proper ultimate level of support for the ANL user activity. This will very much depend on how the specific programs carried out by the ANL groups develop in both physics significance and competitiveness with the entire high energy physics program. We recommend strongly that the R\&D effort rema in closely coupled to the specific needs of the research program.

\section{Accelerator Research}

The development of polarized high energy proton beams at the ZGS has been one of the major achievements of the ANL accelerator group. We feel that this development should certainly be continued to make polarized beams possible at higher energies. We believe that much interesting physics can come out of this field.

ANL proposes to use the Princeton-Pennsylvania Accelerator (PPA) magnets and other components to build an experimental polarized proton storage ring (called PPSR) to study problems involved in this development, including the handling or avoidance of depolarizing resonances in alternating gradient machines, the survival of polarization in long-term storage, possible methods of reversing the sign of polarization during storage, and non-destructive methods of monitoring polarizalion. In addition it is proposed to continue the development of high intensity polarized

$\mathrm{H}^{-}$sources, which promise an order of magnitude improvement, or better, in the polarized beam intensities available. This program is estimated by ANL to take 5 years at a funding level of $\$ 1 \mathrm{M}$ per year.

The goal of this development is the acceleration of polarized beams at higher energy accelerators, first at the Brookhaven Alternating Gradient Synchrotron (AGS) and later at the very high energies of the Fermilab main ring and Doubler, and the Intersecting Storage Accelerator (ISABELLE). Therefore a high priority in this work must be cooperation and coordination 
with polarized beam work at Brookhaven National Laboratory (BNL) and/or Fermiłab; in particular, we recommend that the ANL group spend considerable effort at these laboratories throughout the program.

Although the Subpanel did not have sufficient information to validate the stated costs and schedule of the PPSR project, it is clear that the proposed program addresses the major unsolved problems of high energy polarized proton accelerator physics. We have therefore asked the DOE to convene a small group of experts; who would be given a detajled breakdown of expected costs and schedules by ANL, and who could then provide a confirmation of the Laboratory's estimates.

Assuming that the group of experts concurs with the Laboratory estimates on both time and cost, we believe that the Laboratory should continue with the PPSR project in a way which leads most directly to high energy polarized beams at BNL and/or Fermilab.

\section{User Support Center}

The nätional high energy physics program has made a considerable investment at ANL in the form of facilities such as high bay areas suitable for the assembly of large pieces of equipment, and more specialized facilities such as the Plastics Shop. Further, the whole range of technology associated with accelerators exists there. This includes expertise in magnets, both DC. and pulsed and both conventional and superconducting: puised power supplies; RF technology; vacuum technology; and so on. ANL is àlso a large laboratory with excellent mechanical shops and a large àd varied engineering staff.

While part of these capabilities already exist at some of the large Universities, it would clearly be impractical to duplicate them at every University with a high energy physics program. At the same time many of these capabilities, including the expertise described above, will remain at ANL, redirected toward the ongoing goais and programs of the Laboratory and the DOE. It has been proposed that the Laboratory continue to make the use of these facilities available to the national high energy physics program and that a small liaison group (of roughly two full-time equivalents) be established to facilitate access to these facilities and expertise. The user would pay for the use of these facilitiens, including shop time and materials, on the same basis as the ANI. in-house groups.

To determine the interest in such a User Support Center, the Chairman of this Subpanel sent a letter of inquiry to over 150 of the senior research people in the field. The response was small (perhaps partly because of the short time available) and mixed, apparently depending on the history of each group, its geographic location, and the availability 
of such facilities at the home institution. A significant number of the responses did express an interest in the suggestion, however, and we believe that there is a potential benefit to be derived from such a program. The actual amount of use and the emphasis on various parts of the facility are as yet unclear, and will have to be determined by experience. The initial phase of this operation should be at a low level, and should be viewed as an experiment. The program will have to be monitored and adjusted according to the interest shown by the community and the results obtained. 
REPORT OF THE

EVALUATION GROUP ON THE

PROPOSED ARGONNE NATIONAL LABORATORY

EXPERIMENTAL POLARIZED PROTON STORAGE RING

MEMBERS: Richard Neal (Chairman), Stanford Linear Accelerator Center

Tom Elioff, Lawrence Berkeley Laboratory Hank Hsieh, Brookhaven National Laboratory Russ Huson, Fermi National Accelerator Laboratory Lee Teng, Fermi National Accelerator Laboratory 
THIS PAGE

\section{WAS INTENTIONALLY LEFT BLANK}




\section{STANFORD UNIVERSITY}

Stanford Linear Accelerator Cenjtier

July 7, i 978

Dr. James S, Kanè

Acting Assoctate Director for Basic Research Programs

office of Energy Research

Departinent of Energy

Washington, D.C., 20545

Dear Dr. Kane:

The report of the Evaluation Group on the Proposed ANL Experimental Polarized Proton Storage Ring (PPSR) which met at Argonne on June $30,1978,18$ enclosed.

sincerely,

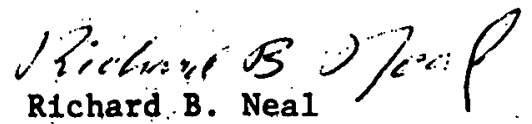

Chatrman

RBN : mm

Enclosure 